\title{
Mediating Role of Emotional Processing Styles in the Relationship between Lateral Superiority, Circadian Rhythm, and Sleep Quality with Attentional Function
}

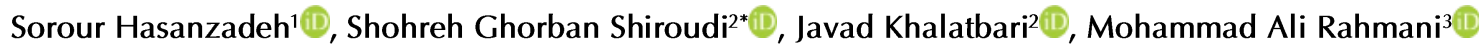 \\ 1 PhD Student of General Psychology, Department of Psychology, Tonekabon Branch, Islamic Azad University, \\ Tonekabon, Iran \\ 2 Associate Professor, Department of Psychology, Tonekabon Branch, Islamic Azad University, Tonekabon, Iran \\ ${ }^{3}$ Assistant Professor, Department of Psychology, Tonekabon Branch, Islamic Azad University, Tonekabon, Iran
}

*Corresponding author: Shohreh Ghorban Shiroudi, Department of Psychology,

Tonekabon Branch, Islamic Azad

University, Tonekabon, Iran

Tel: +989121581822

Email: Drshohrehshiroudi@gmail.com

Received: 27 Mar. 2020 Accepted: 14 Jul. 2020 ePublished: 01 Feb. 2021

\begin{abstract}
Background and Objective: Attention is considered one of the most critical and higher-order activities of the mind and one of the prime characteristics of cognitive structure playing a significant role in the structure of intelligence, memory, and perception. The purpose of this study was to investigate the mediating role of emotional processing styles in the relationship between lateral superiority, circadian rhythm, and sleep quality with attention performance.

Materials and Methods: This descriptive-correlational study was carried out on the undergraduate psychology students $(n=2,300)$ of Islamic Azad University, Islamshahr Branch, Tehran, Iran, within the 2018-2019 academic year using a stratified random sampling method. The Pittsburgh Sleep Quality Index, Morningness-Eveningness Scale (Circadian Rhythm Scale), Lateral Superiority Evaluation Checklist, Emotional Processing Scale, and Selective Attention Test were used to collect data. In this study, both descriptive and inferential statistics were used to analyze the data. The structural equation modeling and SmartPLS software (version 3.2.9) were utilized to investigate the research hypotheses.

Results: The obtained results revealed that emotional processing styles played a mediating role in the relationship between circadian rhythms, lateral superiority, and sleep quality with attention performance. Therefore, it can be said that circadian rhythms, lateral superiority, and sleep quality with a coefficient of $35 \%(P<0.001$; $t$-value=2.382) affected attention performance with the presence of the mediating factor of emotional processing styles.

Conclusions: It can be concluded that emotional processing styles mediate the relationship between sleep quality, lateral superiority, and circadian rhythms with attentional function.
\end{abstract}

Keywords: Attention, Circadian Rhythms, Emotions, Nervous System, Malformations, Sleep

\section{Background}

During recent decades, experts in the field of education have focused on cognitive processes, such as attention performance. Attention is considered one of the most critical and higher-order activities of the mind and one of the prime characteristics of cognitive structure playing a significant role in the structure of intelligence, memory, and perception [1]. The process of attention plays several roles, including the determination of the kind of required information for processing, control of unnecessary information, manipulation of the current information, and reliability of processing for an extended period [2]. Through the regulation and prioritization of stimuli that are processed by the central nervous system, attention acts as the gatekeeper of the mind. One of the influential factors in cognitive functions, such as memory and attention, is rapid eye movement sleep [3].

Sleep is regarded as one of the significant needs of human beings and is among the physiological needs with regard to Maslow's hierarchy of needs. Quality sleep occurs when an individual falls into a deep sleep; therefore, quality sleep is something more than finding a chance to sleep for a few hours [4]. When an individual becomes older, the main changes occur in his/her sleep pattern, structure, and quality bringing about sleep disturbances and consequent frequent complaints [5]. Nevertheless, sleep disorder occurs in all age groups, and it is estimated that one-third of adolescents experience sleep problems [6]. Sleep disorders (e.g., inadequate sleep, poor quality of sleep, and irregular sleep) can influence cognition, emotions, and motor development and bring about physiological changes 
in the brain [7]. In addition, disturbances in the sleep and waking cycle can affect the feeling of exhaustion and lack of concentration [8].

Circadian rhythms are considered a part of biological rhythms, which are a set of constant biological activities, and their duration and amplitude are statistically significant. They are repeated at least during two consecutive periods [9, 10]. Furthermore, the impact of the gravity of the moon has produced a tide that can even control reproduction [11]. Based on their cycle duration, biorhythms are divided into several categories, including ultradian (less than $20 \mathrm{~h}$ ), circadian (within 20 and $28 \mathrm{~h}$ ), and infradian (more than $28 \mathrm{~h}$ ) [12]. The proof of the existence of these internal clocks is that if an individual is placed in an environment with constant light and temperature [13].

Sleep and waking rhythms are the primary factors in creating chronotype or individuals' preferences during periods of sleep and waking [14]. As a result, individuals can be classified under two types, namely morningness and eveningness [15]. These individual differences are genetic and are created based on the endogenous biological clock [16] and influenced by the environment [17]. Numerous studies have revealed that generally morningness is more frequently observed in children and adults and eveningness is more commonly noticed in adolescents [18].

Regarding the cognitive processes and optimal performance time, various studies have compared the two above-mentioned groups. In a study, morningness, in comparison to eveningness, showed higher memory performance even when subjects were tested in the morning [19]. In addition, in another study, short-term memory performance was superior in the morning than that reported in the evening. Furthermore, the impact of circadian rhythm is taken into account as a mediating factor in the psychological field and it can be suitable for cognitive activities, attention capacity, and memory function and lead to the deterioration or enhancement of performance [20]. A circadian pattern regulates memory function, and the peak of performance in short-term memory in the morning group occurs early in the morning and in the evening group occurs during the early hours of the night. The idea of different circadian rhythms shows that functional biological clocks exist in both of the rights and left hemispheres of the human brain [21] and independently function in diverse situations [22-24].

On the other hand, emotion is one of the variables influenced by circadian rhythms and sleep quality. Debarnot et al. [25] demonstrated that there is a relationship between circadian preferences and personality characteristics of impulsivity and emotionality. Tapia-Osoria et al. [26], in their study on rats, observed that disorder in circadian rhythms, which is resulted from being exposed to 8 weeks of nonstop light, deteriorates the suprachiasmatic nucleus and causes depressive and anxiety-like behaviors. Berger et al. [27] showed that the despoiled pattern of circadian rhythms was accompanied by anxiety-provoking tiredness and depressive symptoms. The impact of weekly rhythms on performance has revealed that the early days of the week were associated with minimal temperament, arousal, and workload, and the day before the weekend had different results [28-33].

\section{Objectives}

This study was conducted to determine the mediating role of emotional processing styles in the relationship between sleep quality, lateral superiority, and circadian rhythms with attention performance.

\section{Materials and Methods}

This fundamental descriptive-correlational study was carried out on all the undergraduate psychology students of Islamic Azad University, Islamshahr Branch, Tehran, Iran, $(n=2,300)$ using a stratified random sampling method. Firstly, the total number of the statistical population was determined; secondly, the number of the first-, second-, third-, and fourth-year students in each subgroup was determined; thirdly, after the determination of the sample size, the ratio of each subgroup was estimated and multiplied by the sample size. Finally, it was determined that how many students were needed in each subgroup. The inclusion criteria were an age range of $20-40$ years, no psychological illness, conscious consent to participate in the study, and at least a bachelor's degree. The exclusion criteria of the study were incomplete responses to the study questionnaires.

\section{Morningness-Eveningness Scale (Circadian Rhythm Scale)}

This scale is a 19 multiple-choice self-assessment questionnaire developed by Horne and Ostberg in 1976 to determine an individual's circadian rhythm type. The scores are within the range of 17-76. A higher score indicates a higher level of morningness, and a lower score shows a higher level of eveningness. In numerous studies, it has been reported that this questionnaire has adequate internal consistency. The internal consistency of the questions was within the range of -0.02 to +0.61 , with a mean of +2.2 . Furthermore, the Cronbach's alpha of the questionnaire was reported as 0.77 [34]. 
Lateral Superiority Evaluation Checklist

This checklist was developed by Chapman [35] and included 13 items extracted from the best materials of valid questionnaires. The answers to each item are specified based on the selection of one of three options, including right hand (score 1), both hands (score 2), and left hand (score 3). As a result, the scores are within the range of 13 (perfectly right-sided) to 39 (perfectly left-sided). Individuals with scores within the range of 13-17 are categorized as right-handed (right-dominant), and those with scores within the range of 18-39 are classified as left-handed (left-dominant) and ambidextrous. The internal consistency and retest reliability of this scale were reported as 0.96 and 0.97 , respectively. In addition, the correlation of this scale with a behavioral assessment of hand lateral superiority was 0.83 . The reliability of this questionnaire using Cronbach's alpha, split-half, and test-retest were $0.94,0.94$, and 0.92, respectively [35].

\section{Pittsburgh Sleep Quality Index}

This instrument was designed by Boyce et al. in 1989. This 9-item questionnaire is employed to measure the quality of sleep over the past month. Items 1 and 3 are essay items, and the rest are multiple-choice items. The total score of this questionnaire is within the range of 0-21. A score of 0 to 4 indicates the desired quality of sleep, and a score of 5 or higher shows the poor quality of sleep. This questionnaire includes seven components, namely subjective sleep quality, sleep latency, sleep duration, habitual sleep efficiency, sleep disturbances, use of sleeping medication, and daytime dysfunction. The reliability of the Persian version of this index was reported as 0.89 [36].

\section{Emotional Processing Scale}

This scale was developed by Bakker et al. in 2007 and is a 38-item self-report scale that is used for the measurement of emotional processing styles. Each item is scored on a 5-point Likert scale (never: score 1 to almost always: score 5). Therefore, in this scale, the minimum and maximum scores are 38 and 190, respectively. The scale has eight subscales, namely intrusion, suppression, lack of attunement, lack of control, disassociation, avoidance, discordance, and externalization. The items related to each component are 1-8 (intrusion), 9-12 (suppression), 13-17 (lack of attunement), 18-21 (lack of control), 22-25 (disassociation), 26-28 (avoidance), 29-35 (discordance), and 36-38 (externalization). The coefficients of Cronbach's alpha and test-retest reliability of this scale were 0.92 and 0.79 , respectively. Moreover, the Cronbach's alpha coefficient of this scale was reported as 0.95 [37].

\section{D2 Selective Attention Test}

This test measures the degree of focus (i.e., selective attention) based on the spectrum of general functions. The $\mathrm{d} 2$ test puts the subjects in front of the task of selecting visual target stimuli from an assembly of different visual stimuli that are culturally independent. In order to measure the internal consistency of $\mathrm{d} 2$ test scales, various external studies have been conducted in different statistical societies. All of the coefficients in these studies, including Spearman and Guttman split-half methods and Cronbach's alpha, were higher than 0.90 , indicating very high reliability of the scales of the $\mathrm{d} 2$ test $[38,39]$.

In the present study, two types of descriptive and inferential statistics were employed to analyze the data. Firstly, the values of descriptive statistics (i.e., frequency, percentage, mean, standard deviation, and minimum and maximum scores) regarding the characteristics of the sample and variables under study were determined, and then the structural equation modeling and SmartPLS software (version 3.2.9) were employed to analyze data.

\section{Results}

Demographic information included the age and gender of the participants. Firstly, the frequency distribution of the variable of gender in the present study was investigated.

Table 1 shows that $48 \%(n=96)$ and $52 \%(n=104)$ of the respondents were male and female, respectively.

In examining the study hypothesis, it was shown that emotional processing styles played a mediating role in the relationship between circadian rhythms, lateral superiority, and sleep quality with attention

Table 1. Frequency distribution of the study participants based on gender

\begin{tabular}{lcccc}
\hline Qualitative variable & Level & $\begin{array}{c}\text { Frequency } \\
(\mathbf{n})\end{array}$ & $\begin{array}{c}\text { Frequency } \\
(\mathbf{\%})\end{array}$ & $\begin{array}{c}\text { Cumulative frequency } \\
(\mathbf{\%})\end{array}$ \\
\hline \multirow{2}{*}{ Gender } & Male & 96 & 48 & 48 \\
& Female & 104 & 52 & 100 \\
Age & Under 30 & 96 & 49 & 49 \\
(year) & $30-35$ & 38 & 19 & 68 \\
& $36-40$ & 29 & 14.5 & 82.5 \\
& $41-45$ & 21 & 10.5 & 93 \\
\end{tabular}


Table 2. Central tendency and scatter of study variables

\begin{tabular}{|c|c|c|c|c|c|}
\hline Variable & Mean & Standard deviation & Skewness & Standard error of skewness & Kurtosis \\
\hline General memory confidence & 3.8836 & 0.58460 & -0.674 & 0.172 & -0.032 \\
\hline Confidence in decision making & 3.832 & 0.58022 & -0.183 & 0.172 & -0.140 \\
\hline Confidence in focus & 4.1275 & 0.77126 & -1.185 & 0.172 & -0.140 \\
\hline Cognitive perfectionism & 3.995 & 0.69091 & -0.813 & 0.172 & 1.064 \\
\hline Intrusion & 4.21188 & 0.63562 & -1.351 & 0.172 & 3.409 \\
\hline Suppression & 4.48 & 0.55781 & -1.045 & 0.172 & 0.015 \\
\hline Lack of attunement & 4.35 & 0.57511 & -0.666 & 0.172 & -0.518 \\
\hline Lack of control & 4.345 & 0.62585 & -0.676 & 0.172 & -0.497 \\
\hline Disassociation & 4.5375 & 0.47338 & -0.819 & 0.172 & -0.336 \\
\hline Avoidance & 4.4171 & 0.54192 & -1.331 & 0.172 & 3.150 \\
\hline Discordance & 4.3842 & 0.48215 & -0.771 & 0.172 & 0.970 \\
\hline Externalization & 4.0638 & 0.64658 & -0.657 & 0.172 & 0.170 \\
\hline Circadian rhythms & 4.2086 & 0.50575 & -0.382 & 0.172 & -0.712 \\
\hline Reliance on cognition and memory & 3.9605 & 0.58321 & -0.845 & 0.172 & 0.849 \\
\hline Emotional processing & 4.3502 & 0.42299 & -0.960 & 0.172 & 1.064 \\
\hline
\end{tabular}

performance (Table 2). Therefore, it can be said that circadian rhythms, lateral superiority, and sleep quality with a coefficient of $35 \%$ (confidence level $=0.95 ; \quad \mathrm{t}$-value $=2.382$ ) affected attention performance with the presence of the mediating factor of emotional processing styles (Table 3).

Table 3. Estimates of direct effect coefficients

\begin{tabular}{|c|c|c|c|}
\hline Path & Factor loading & t-value & P-value \\
\hline Circadian rhythms, sleep quality, and lateral superiority $\rightarrow$ & 0.465 & 4.354 & \\
\hline attention performance (emotional processing styles of the mediating variable) & 0.359 & 2.392 & 0.0001 \\
\hline Sleep quality $\rightarrow$ attention performance (emotional processing styles of the mediating variable) & 0.66 & 0.864 & 0.625 \\
\hline Lateral superiority $\rightarrow$ attention performance (emotional processing styles of the mediating variable) & 0.423 & 3.178 & 0.0001 \\
\hline Circadian rhythms $\rightarrow$ attention performance (emotional processing styles of the mediating variable) & 0.268 & 2.436 & 0.0001 \\
\hline $\begin{array}{l}\text { Circadian rhythms, sleep quality, and lateral superiority } \rightarrow \\
\text { attention performance (emotional processing styles of the mediating variable) }\end{array}$ & 0.35 & 2.382 & 0.0001 \\
\hline
\end{tabular}

\section{Discussion}

The results revealed that emotional processing styles played a mediating role in the relationship between sleep quality, lateral superiority, and circadian rhythms with attention performance and the proposed model has a suitable fitting (goodness of fit). The findings of the correlation of the model variables can be referred to in supporting the proposed model. In addition, Tamm et al. [29], in their study, showed that considering the relationship between sleep quality and emotional processing styles, there is a correlation between sleep physiology and emotional processing. Likewise, Barger et al. [11] demonstrated that toddlers, when suffering from sleep deprivation, are not only unable to fully utilize their positive emotional experiences but also cannot adjust themselves to the challenging circumstances.

Concerning the relationship between sleep quality and attention performance, the results of a study carried out by Watson et al. [16] showed that insomnia symptoms and variable sleep duration continuously accompany dimensions of attention deficit which is in line with the findings of studies conducted by Tamm et al. [29] and Pauls et al. [34]. Allison et al. [36] showed that sleep deprivation had a significant impact on selective and continuous attention. Furthermore, Lam et al. [30] demonstrated a reverse relationship between midday sleep with nighttime sleep and auditory attention domain. It was indicated that midday sleep had a negative correlation with neural performance, and nighttime sleep is indispensable for the development of cognitive performance. In explaining the findings, it can be said that better sleep quality can facilitate brain development as well as neurological performance. It prevents responding to harmful stimuli, implying that due to poor sleep quality, individuals lose their ability to maintain attention and inaccurately reject to respond to unemotional stimuli. These results are in line with the findings of a study carried out by De Schotten et al. [24], showing that attention control has a relationship with sleep quality in older individuals.

Concerning the correlation between lateral superiority and attention performance, the results of a study performed by Austin et al. [37] are consistent with the findings of the present study indicating that when the attention was focused on the right side, the right-handed subjects showed more orientation than the left-handed participants and the right-handed individuals could change their attention better than the left-handed cases. In explaining this finding, the pattern of specialization of brain hemispheres can be pointed to indicating that the right brain hemisphere is ascribed to processes of attention to everyday affairs.

Regarding the correlation between circadian rhythms 
and emotional processing styles, the findings of studies conducted by Pereira and Khan [38] and Langner and Eickhoff [39] are in line with the results of the present study. As Abdel Rahman [40] showed, eveningness was associated with increased suppression, and morningness was accompanied by increased cognitive evaluation. In addition, Emmorey [41] demonstrated that individuals with the morning type in comparison to both the evening and intermediate types had a higher level of positive affect and a lower level of negative affect. According to Wright et al. [42], when waking occurs at a proper biological time, daily working is advantageous for an emotional performance. Nevertheless, when waking occurs at an unsuitable biological time, due to environmental pressures (e.g., jet lag, early school start time, long working hours, and shift work) or sleep disorders in circadian rhythms, the results of discord between the circadian cycle and sleep physiology leads to emotional dysfunction.

\section{Conclusions}

It can be concluded that emotional processing styles mediate the relationship between sleep quality, lateral superiority, and circadian rhythms with attention performance.

\section{Compliance with ethical guidelines}

All ethical principles were observed in this study. The participants were informed about the purpose of the study and implementation of the stages. In addition, informed consent was obtained from all the study subjects. The participants were also assured of the confidentiality of their information. Moreover, the subjects were free to withdraw from the study at any time, and the results of the study would be available to them if desired. This article is based on a PhD dissertation in Psychology at Islamic Azad University of Tonekabon International Branch.

\section{Acknowledgments}

The authors would like to express their gratitude to the participants who greatly cooperated in conducting the study.

\section{Authors' contributions}

Conceptualization [Sorour Hasanzadeh]; Methodology [Shohreh Ghorban Shiroudi]; Investigation [Javad Khalatbari]; Writing Original Draft [Sorour Hasanzadeh]; Writing, Reviewing, and Editing [All authors]; Funding Acquisition [All authors]; Resources [All authors]; Supervision [Mohammad Ali Rahmani]

\section{Funding/Support}

The current study did not receive any specific grant from funding agencies in public, commercial, or not-for-profit sectors.

\section{Conflicts of Interest}

The authors declare that there is no conflict of interest.

\section{References}

1. Aase I, Kompus K, Gisselgård J, Joa I, Johannessen JO, Brønnick K. Language lateralization and auditory attention impairment in young adults at ultra-high risk for psychosis: A dichotic listening study. Frontiers in Psychology. 2018; 9(2):3250. [DOI:10.3389/fpsyg.2018.00608] [PMID] [PMCID]

2. Aguiar SA, Barela JA. Sleep deprivation affects sensorimotor coupling in postural control of young adults. Neuroscience Letters. 2014; 574:47-52. [DOI:10.1016/j.neulet.2014.05.028] [PMID]

3. Adan A, Archer SN, Hidalgo MP, Di Milia L, Natale V, Randler C. Circadian typology: a comprehensive review. Chronobiology International. 2012; 29(9):1153-75. [DOI:10.3109/07420528.2012.719971] [PMID]

4. Allen RP, Chen C, Garcia-Borreguero D, Polo O, DuBrava $\mathrm{S}$, Miceli J, et al. Comparison of pregabalin with pramipexole for restless legs syndrome. The New England Journal of Medicine. 2014; 370(7):621-31. [DOI: 10.1056/NEJMoa1303646] [PMID]

5. Aly $M$, Moscovitch $M$. The effects of sleep on episodic memory in older and younger adults. Memory. 2010; 18(3):327-34. [DOI:10.1080/09658211003601548] [PMID]

6. Barclay NL, Myachykov A. Sustained wakefulness and visual attention: moderation by chronotype. Experimental Brain Research. 2017; 235(1):57-68. [DOI:10.1007/s00221016-4772-8] [PMID] [PMCID]

7. Becerril K, Barch D. Influence of emotional processing on working memory in schizophrenia. Schizophrenia Bulletin. 2011; 37(5):1027-38. [DOI:10.1093/schbul/sbq009] [PMID] [PMCID]

8. Beebe DW. Cognitive, behavioral, and functional consequences of inadequate sleep in children and adolescents. Pediatric Clinics of North America. 2011; 58(3):649-65. [DOI:10.1016/j.pcl.2011.03.002] [PMID] [PMCID]

9. Berdynaj D, Boudissa SN, Grieg MS, Hope C, Mahamed SH, Norbury R. Effect of chronotype on emotional processing and risk taking. Chronobiology International. 2016; 33(4):406-18. [DOI:10.3109/07420528.2016.1146739] [PMID]

10. Berger AM, Wielgus K, Hertzog M, Fischer P, Farr L. Patterns of circadian activity rhythms and their relationships with fatigue and anxiety/depression in women treated with breast cancer adjuvant chemotherapy. Supportive Care in Cancer. 2010; 18(1):105-14. [DOI:10.1007/s00520-0090636-0] [PMID]

11. Berger RH, Miller AL, Seifer R, Cares SR, Lebourgeois MK. Acute sleep restriction effects on emotion responses in 30to 36-month-old children. Journal of Sleep Research. 2012; 21(3):235-46. [DOI:10.1111/j.1365-2869.2011.00962.x] [PMID] [PMCID]

12. Bernstein JPK, Calamia M, Keller JN. Multiple self-reported sleep measures are differentially associated with cognitive performance in community-dwelling nondemented elderly. Neuropsychology. 2018; 32(2):220-9. [DOI:10.1037/ neu0000407] [PMID]

13. Best JR, Miller PH. A developmental perspective on executive function. Child Development. 2010; 81(6):1641-60. [DOI:10.1111/j.1467-8624.2010.01499.x] [PMID] [PMCID]

14. Bjork RA, Dunlosky J, Kornell N. Self-regulated learning: beliefs, techniques, and illusions. Annual Review of Psychology. 2013; 64(1):417-44. [DOI:10.1146/annurevpsych-113011-143823] [PMID]

15. Blake $A B$, Castel AD. On belief and fluency in the construction of judgments of learning: assessing and altering the direct effects of belief. Acta Psychologica. 2018; 186:2738. [DOI:10.1016/j.actpsy.2018.04.004] [PMID]

16. Watson $A B$, Ahumada AJ. Blur clarified: a review and synthesis of blur discrimination. Journal of Vision. 2011; 11(5):10. [DOI:10.1167/11.5.10] [PMID]

17. Cappuccio FP, D'Elia L, Strazzullo P, Miller MA. Quantity and quality of sleep and incidence of type 2 diabetes: a systematic review and meta-analysis. Diabetes Care. 2010; 33(2):414-20. [DOI:10.2337/dc09-1124] [PMID] [PMCID]

18. Carciofo R. Morningness-eveningness and affect: the mediating roles of sleep quality and metacognitive beliefs. Sleep and Biological Rhythms. 2020; 18(1):17-26. [DOI:10.1007/s41105-019-00238-9]

19. Naveh-Benjamin M, Ohta N. Memory and aging: current issues and future directions. East Sussex: Psychology Press; 2012. P. $1-428$ 
20. Chellappa SL, Morris CJ, Scheer FA. Effects of circadian misalignment on cognition in chronic shift workers. Scientific Reports. 2019; 9(1):699. [DOI:10.1038/s41598018-36762-w] [PMID] [PMCID]

21. Chraif M. The influence of sleep deprivation on short term memory and attention to details in young students. Procedia-Social and Behavioral Sciences. 2012; 33:1052-6. [DOI:10.1016/j.sbspro.2012.01.283]

22. Chung MH, Liu WI, Lee HL, Hsu N. Selected neurophysiological, psychological, and behavioral influences on subjective sleep quality in nurses: a structure equation model. PLoS One. 2013; 8(11):e79529. [DOI:10.1371/ journal.pone.0079529] [PMID] [PMCID]

23. Cleator J, Abbott J, Judd P, Wilding JPH, Sutton CJ. Correlations between night eating, sleep quality, and excessive daytime sleepiness in a severely obese UK population. Sleep Medicine. 2013; 14(11):1151-6. [DOI:10.1016/j.sleep.2013.04.026] [PMID]

24. De Schotten MT, Dell'Acqua F, Forkel SJ, Simmons A, Vergani F, Murphy DG, et al. A lateralized brain network for visuospatial attention. Nature Neuroscience. 2011; 14(10):1245-6. [DOI:10.1038/nn.2905] [PMID]

25. Debarnot U, Castellani E, Valenza G, Sebastiani L, Guillot A. Daytime naps improve motor imagery learning. Cognitive, Affective \& Behavioral Neuroscience. 2011; 11(4):541-50. [DOI:10.3758/s13415-011-0052-z] [PMID]

26. Ruocco AC, Medaglia JD, Ayaz H, Chute DL. Abnormal prefrontal cortical response during affective processing in borderline personality disorder. Psychiatry Research. 2010; 182(2):117-22. [DOI:10.1016/j.pscychresns.2010.01.011] [PMID]

27. Ahrberg K, Dresler M, Niedermaier S, Steiger A, Genzel L. The interaction between sleep quality and academic performance. Journal of Psychiatric Research. 2012; 46(12):1618-22. [DOI:10.1016/j.jpsychires.2012.09.008] [PMID]

28. Van der Velde J, Servaas MN, Goerlich KS, Bruggeman R, Horton P, Costafreda SG, et al. Neural correlates of alexithymia: a meta-analysis of emotion processing studies. Neuroscience and Biobehavioral Reviews. 2013; 37(8):177485. [DOI:10.1016/j.neubiorev.2013.07.008] [PMID]

29. Tamm L. Attention-deficit hyperactivity disorder. The curated reference collection in neuroscience and biobehavioral psychology. New York: Elsevier Science; 2016. P. 617-24.

30. Berteotti C, Cerri M, Luppi M, Silvani A, Amici R. An overview of sleep physiology and sleep regulation.
Milestones in Drug Therapy. 2015;6(1):3-23. [DOI:10.1007/ 978-3-319-11514-6_1]

31. Jones SG, Benca RM. Circadian disruption in psychiatric disorders. Sleep Medicine Clinics. 2015; 10(4):481-93. [DOI:10.1016/j.jsmc.2015.07.004] [PMID]

32. Baglioni C, Spiegelhalder K, Lombardo C, Riemann D. Sleep and emotions: a focus on insomnia. Sleep Medicine Reviews. 2010; 14(4):227-38. [DOI:10.1016/j.smrv.2009. 10.007] [PMID]

33. Ashworth A, Hill CM, Karmiloff-Smith A, Dimitriou D. Sleep enhances memory consolidation in children. Journal of Sleep Research. 2014; 23(3):302-8. [DOI:10.1111/jsr. 12119] [PMID]

34. Pauls DL, Abramovitch A, Rauch SL, Geller DA. Obsessivecompulsive disorder: an integrative genetic and neurobiological perspective. Nature Reviews Neuroscience. 2014; 15(6):410-24. [DOI:10.1038/nrn3746] [PMID]

35. Conley CS, Durlak JA, Kirsch AC. A Meta-analysis of universal mental health prevention programs for higher education students. Prevention Science. 2015; 16(4):487507. [DOI:10.1007/s11121-015-0543-1] [PMID]

36. Allison KC, Spaeth A, Hopkins CM. Sleep and eating disorders. Current Psychiatry Reports. 2016; 18(10):92. [DOI:10.1007/s11920-016-0728-8] [PMID]

37. Austin G, Groppe K, Elsner B. The reciprocal relationship between executive function and theory of mind in middle childhood: a 1-year longitudinal perspective. Frontiers in Psychology. 2014; 5:655. [DOI:10.3389/fpsyg.2014.00655] [PMID] [PMCID]

38. Pereira DM, Khan A. Brain lateralization of emotional processing in depression. Depression. 2017; 2:25-36. [DOI:10.5772/66828]

39. Langner R, Eickhoff SB. Sustaining attention to simple tasks: a meta-analytic review of the neural mechanisms of vigilant attention. Psychological Bulletin. 2013; 139(4):870-900. [DOI:10.1037/a0030694]

40. Abdel Rahman TT. Development and standardization of Arabic words in noise test in Egyptian children. International Journal of Pediatric Otorhinolaryngology. 2018; 108:1-7. [DOI:10.1016/j.ijporl.2017.11.019] [PMID]

41. Emmorey K, Mehta S, McCullough S, Grabowski TJ. The neural circuits recruited for the production of signs and fingerspelled words. Brain and Language. 2016; 160:30-41. [DOI:10.1016/j.bandl.2016.07.003] [PMID] [PMCID] 